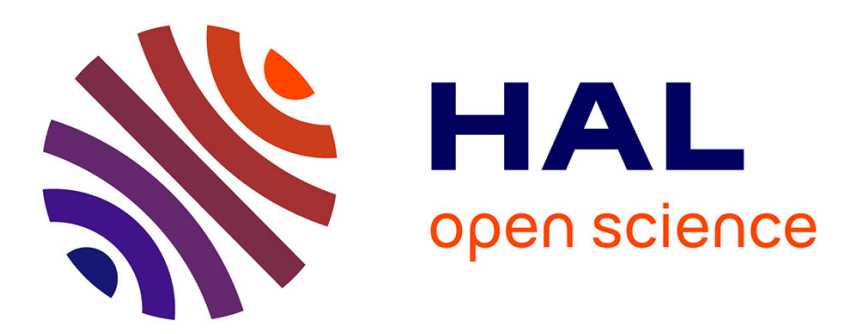

\title{
Comparaison de la réceptivité de différents sols et substrats de culture aux fusarioses vasculaires
}

Claude Alabouvette, Yvonne Couteaudier, Jean Louvet, Paul Bremeersch

\section{To cite this version:}

Claude Alabouvette, Yvonne Couteaudier, Jean Louvet, Paul Bremeersch. Comparaison de la réceptivité de différents sols et substrats de culture aux fusarioses vasculaires. Agronomie, 1982, 2 (1), pp.1-6. hal-00884345

\section{HAL Id: hal-00884345 \\ https://hal.science/hal-00884345}

Submitted on 1 Jan 1982

HAL is a multi-disciplinary open access archive for the deposit and dissemination of scientific research documents, whether they are published or not. The documents may come from teaching and research institutions in France or abroad, or from public or private research centers.
L'archive ouverte pluridisciplinaire HAL, est destinée au dépôt et à la diffusion de documents scientifiques de niveau recherche, publiés ou non, émanant des établissements d'enseignement et de recherche français ou étrangers, des laboratoires publics ou privés. 


\title{
Comparaison de la réceptivité de différents sols et substrats de culture aux fusarioses vasculaires
}

\author{
Claude ALABOUVETTE, Yvonne COUTEAUDiER \& Jcan LOUVET \\ avec la collaboration technique de Paul BREMEERSCH \\ I.N.R.A., Station de Recherches sur la Flore pathogène dans le Sol, 17, rue Sully, F 21034 Dijon Cedex.
}

RÉSUMÉ

Réceptivité des sols, Fusarium oxysporum, Substrats de culture,

Sols résistants,

Méthodologie.
Les principaux facteurs qui conditionnent la gravité d'une maladie d'origine tellurique sont l'infectivité du sol et la réceptivité de la culture. L'infectivité du sol se décompose en deux types de facteurs concernant l'inoculum et les effets de l'environnement-sol sur cet inoculum. La notion de réceptivité du sol à une maladie traduit tous les effets de l'environnement-sol qui modulent l'activité de l'agent pathogène. Dans des conditions expérimentales fixées et en présence d'un inoculum déterminé, la gravité de la maladie est directement fonction de la réceptivité du sol. Concrètement, dans un sol très réceptif, qualifié de sensible, une faible densité d'inoculum suffit à provoquer des dégâts importants alors que dans un sol très peu réceptif, qualifié de résistant, la maladic ne se manifeste, pas même en présence d'une forte concentration d'inoculum.

Le but de cet article est d'illustrer la notion de réceptivité des sols aux fusarioses vasculaires et de proposer une méthode de comparaison de la réceptivité des différents sols et substrats de culture. Le choix du modèle lin-Fusarium oxysporum f. sp. lini permet de miniaturiser les essais et de définir avec une précision satisfaisante des niveaux de réceptivité intermédiaires entre la résistance extrême des terres de Châteaurenard et la sensibilité de la terre d'Ouroux. Cette méthode permet en outre d'analyser l'effet de différents facteurs tels que la mise en culture ou l'apport de sol résistant sur le niveau de réceptivité des substrats de culture.

\section{SUMMARY}

Soil receptivity, Fusarium oxysporum, Suppressive soils, Methodology,

Peats.

\section{A comparison of the receptivity of soils and peats to Fusarium wilts}

The severity of a soil-borne fungal disease is determined mainly by crop receptivity and soil infectivity, the latter being attributable in turn to characteristics of the inoculum and of the soil environment.

The concept of receptivity of a soil to a disease comprises all those soil factors which modify the activity of the pathogen. Thus, for a given inoculum under controlled experimental conditions, disease severity varies directly with soil receptivity. Hence, in a conducive soil, a low inoculum density is sufficient to establish a severe disease whereas in a suppressive soil the disease is not even evident at high inoculum density. In this paper the concept of soil receptivity to Fusarium wilts is illustrated, and a method is proposed for comparing the receptivity of different substrates. Using a small scale experimental system of flax-Fusarium oxysporum f.sp. lini, minor variation in soil receptivity, ranging from the extreme suppressiveness of Châteaurenard soil to the conduciveness of Ouroux soil, could be determined with satisfactory precision. Moreover, modification of the receptivity of peats through cropping or amendment with suppressive soil could be studied.

\section{INTRODUCTION}

Les Fusarium oxysporum (Schlecht.) Snyder et Hansen agents de trachéomycoses sont des champignons menant une vie active dans les sols avant de pénétrer dans les racines de leurs plantes-hôtes. De ce fait, la gravité des maladies qu'ils occasionnent est fonction d'interactions qui s'exercent non seulement au niveau des plantes mais également dans les sols.

BAKER et al. (1967), BAKER (1968), puis LOUVET (1973) ont présenté sous forme schématique les principaux facteurs qui conditionnent le niveau des dégâts provoqués par les champignons pathogènes telluriques. Actuellement, nous proposons la formule condensée suivante :

Niveau de maladie $=f$ (infectivité $d u$ sol, réceptivité de la culture).
L'expression «infectivité du sol», employée ici dans le sens donné à inoculum potential par ZENTMEYER et al. (1944), à soil infectivity par HORNBY (1975) et à potentiel infectieux $d u$ sol par ВоUнот (1980), désigne la capacité d'un sol infesté à provoquer une maladie plus ou moins grave $\left({ }^{1}\right)$. Cette infectivité du sol peut se décomposer en 2 types d'éléments : d'une part l'inoculum, caractérisé par sa densité, ses capacités saprophytiques et infectieuses, d'autre part les effets de l'environnement-sol sur cet inoculum. La notion de réceptivité du sol à une maladie traduit

(1) L'emploi de l'expression « infectivité du sol " est proposé ici de préférence à «potentiel infectieux du sol» afin d'éviter la confusion avec des expressions telles que "potentiel de l'inoculum " utilisée pour décrire une propriété de l'inoculum lui-même, indépendamment du milieu. 
tous ces effets de l'environnement-sol qui modulent l'activité de l'agent infectieux. Nous définissons la réceptivité d'un sol comme sa capacité à permettre l'installation, le développement et la conservation de l'agent infectieux ainsi que l'expression de son pouvoir pathogène sur une population de plantes-hôtes.

Cette notion souligne le fait que, pour les maladies d'origine tellurique, le sol est un intermédiaire obligatoire entre l'agent pathogène et la plante, ce qui peut être exprimé par la formule suivante :

Niveau de maladie $=f$ (inoculum, réceptivité $d u$ sol, réceptivité de la culture).

La réceptivité de la culture est fonction de différents facteurs mais, dans le cadre de cet article dont le but est l'étude de la réceptivité du sol, nous expérimentons dans des conditions déterminées telles que le facteur réceptivité de la culture soit constant.

Dans ce cas, le niveau de la maladie n'est plus fonction que de l'inoculum et de la réceptivité du sol. En d'autres termes, dans des conditions climatiques et culturales définies et pour un inoculum donné, la gravité de la maladie est directement fonction de la réceptivité du sol. Concrètement, on constate que, dans certains sols, la présence d'un très faible nombre de $F$. oxysporum pathogènes suffit à provoquer des dégâts importants de fusariose vasculaire alors que, dans d'autres sols, la maladie ne se manifeste pas même en présence d'une forte concentration d'inoculum (Alabouvette et al., 1979). Dans le premier cas les sols sont qualifiés de sensibles (conducive, en anglais) et dans le second de résistants (suppressive). Entre ces deux extrêmes, il existe toute une gamme de comportements intermédiaires et le but de cet article est de montrer que l'on peut expérimentalement comparer le niveau de réceptivité aux fusarioses vasculaires de différents sols ou de substrats destinés aux cultures maraîchères et horticoles.

\section{MATÉRIEL ET MÉTHODES}

\section{A. Principe de l'expérimentation}

De la formule qui vient d'être énoncée, il ressort que pour comparer la réceptivité de différents sols il suffit, dans des conditions climatiques et culturales définies, de faire varier la densité d'inoculum et d'enregistrer les variations correspondantes de la mortalité des plantes.

Pratiquement, on apporte à chacun des sols à étudier des quantités croissantes d'un inoculum standard et on observe les évolutions corrélatives de la mortalité. En fait, on cherche à reproduire au laboratoire, dans des conditions contrôlées, les phénomènes qui se déroulent normalement au champ lors d'infestations accidentelles des sols.

Etant donné que la réceptivité du sol est la résultante de tous les effets de l'environnement biotique et abiotique sur l'inoculum, il est important de perturber le moins possible les équilibres microbiens du sol dont on veut évaluer la réceptivité. C'est pourquoi l'inoculum est apporté sous forme de propagules conservées dans du talc (TELLO-MARQUINA et al., 1980), support physicochimique inerte qui n'apporte aucune autre microflore que le parasite considéré. D'emploi facile, le talc permet d'effectuer des dilutions précises et assure une bonne répartition de l'inoculum dans le sol ou le substrat considéré.

Après infestation du sol par le parasite, des plantes sont cultivées dans des conditions climatiques déterminées, favorables à l'expression de la maladie. Le taux de plantes mortes est noté à intervalles de temps réguliers (1 semaine), la notation finale servant à établir les courbes de mortalité.

\section{B. Conditions expérimentales}

1. Couple melon-F. oxysporum f.sp. melonis Snyder et Hansen

- infestation à doses croissantes comprises entre 250 et 4000 germes de F.o. f.sp. melonis par $\mathrm{ml}$ de sol, humidification à 60 p. 100 de la capacité de rétention et mise en incubation pendant $15 \mathrm{j}$ à $20^{\circ} \mathrm{C}$.

- répartition en 10 pots de $500 \mathrm{ml}$ par traitement et repiquage dans chaque pot d'une plantule de melon sensible, variété «Charentais », élevée en terreau désinfecté.

- conduite de l'essai en serre, pendant 3 mois, dans des conditions de température comprise entre 18 et $25^{\circ} \mathrm{C}$.

\section{Couple lin-F. oxysporum f.sp. lini (Bolley) Snyder et Hansen}

- infestation à des doses croissantes comprises entre 125 et 4000 germes de F.o. f.sp. lini par ml de sol ou de substrat.

- pour chaque traitement, répartition en 8 à 12 pots de $250 \mathrm{ml}$ et semis, dans chaque pot, de 5 graines de lin sensible, variété "Héra ".

- conduite de l'essai en chambre climatisée, pendant 6 semaines en conditions strictement contrôlées ; température de $15^{\circ} \mathrm{C}$ la nuit, $25^{\circ} \mathrm{C}$ le jour, photopériode de $15 \mathrm{~h}$ à 16000 lux.

\section{Les sols et substrats}

De nombreux sols ont été utilisés. Parmi ceux-ci, les 4 sols dénommés « Ouroux », «Sully », « Dijon» et «Châteaurenard" ont été le plus fréquemment étudiés. Ils diffèrent considérablement à la fois par leur origine géographique, leurs caractéristiques agronomiques et leur passé cultural. Les sols d'Ouroux et Châteaurenard proviennent de 2 régions traditionnelles de cultures maraîchères intensives, la vallée de la Saône et celle de la Durance. Le premier, sablo-argileux, est prélevé dans une prairie ; le second, limono-argileux, est prélevé dans diverses exploitations maraîchères. Leurs caractéristiques agronomiques ont été publiées (AlabouvetTe et al., 1980b). Le sol de Dijon, argileux, est prélevé dans une prairie. La terre de Sully est un mélange horticole utilisé pour les cultures en pots ; il est composé de 50 p. 100 de terre d'Ouroux améliorée par apport de terreau et de tourbe. Elle est donc beaucoup plus riche en matière organique que les 3 autres terres.

Les substrats de culture étudiés sont des substrats commercialisés pour les cultures « hors-sol »; ils sont très différents du point de vue agronomique et de composition variée :

- substrat 1: tourbe blonde 35 p. 100 , tourbe noire 35 p. 100 , écorces de pin non compostées 30 p. 100.

- substrat 2: mélange de tourbes brunes.

- substrat $3:$ tourbe blonde finlandaise non amendée.

\section{RÉSULTATS}

Les quelques exemples présentés dans cet article, représentatifs d'un nombre d'essais beaucoup plus important, ont pour but d'illustrer le concept de réceptivité des sols aux 
fusarioses vasculaires et de montrer l'intérêt d'une méthode d'évaluation du niveau de réceptivité des sols.

\section{A. Comparaison du niveau de réceptivité de 4 sols}

La figure 1 montre les pourcentages de mortalité de melons cultivés dans 4 sols infestés par des doses croissantes de F.o. f.sp. melonis.

Il apparaît clairement que le sol d'Ouroux est extrêmement sensible à la fusariose, car une mortalité importante (80 p. 100) se manifeste déjà avec la dose d'infestation la plus faible (250 germes par $\mathrm{ml}$ ).

Au contraire, il faut atteindre la dose de 4000 germes par $\mathrm{ml}$ pour voir apparaître 20 p. 100 de mortalité dans le sol de Châteaurenard dont la résistance aux fusarioses vasculaires a déjà été démontrée (LOUVET et al., 1976).

Les sols de Sully et Dijon manifestent une réceptivité intermédiaire entre ces 2 extrêmes, mais le manque de précision lié au modèle melon-F.o. f.sp. melonis ne permet pas de connaître le niveau relatif de réceptivité.

En raison de la place et du volume de sol limités, les essais réalisés avec le melon ne comportent que 10 plantes par traitement. Ce faible nombre de répétitions explique l'imprécision et les irrégularités constatées dans les courbes de mortalité.

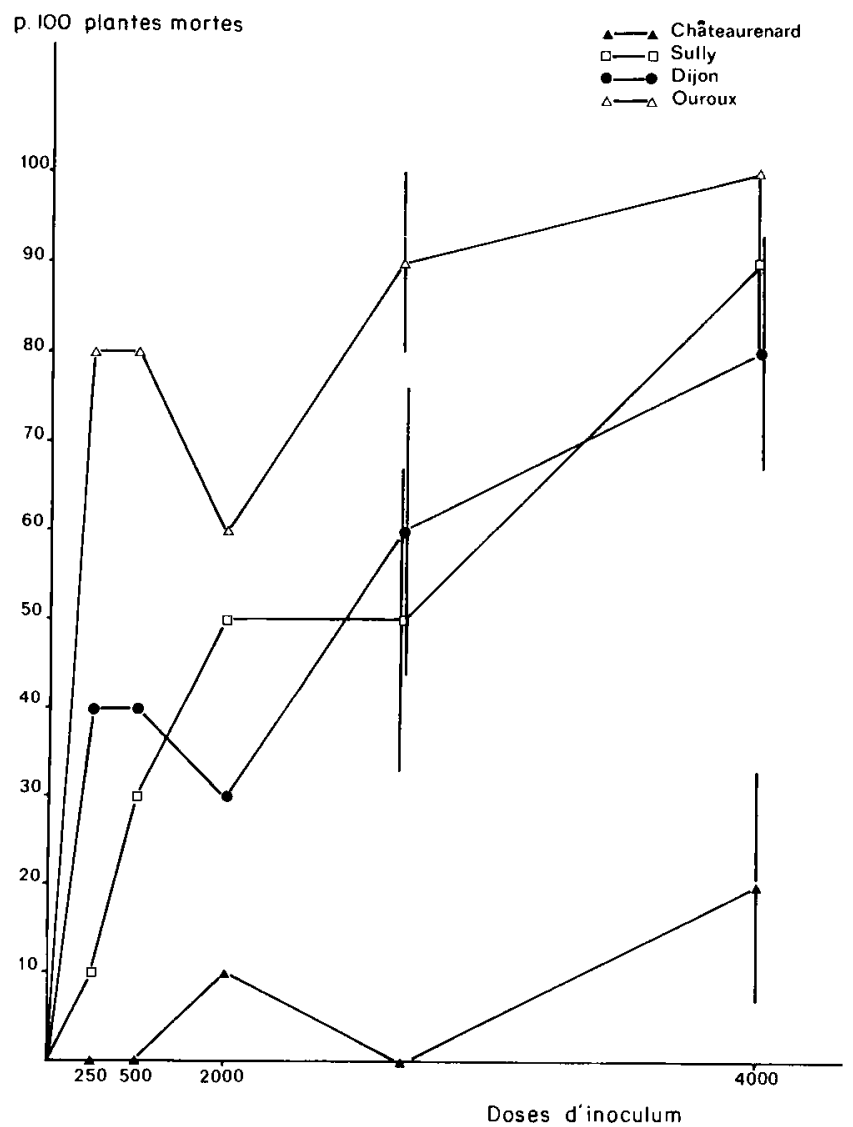

Figure 1

Réceptivité de 4 sols à la fusariose vasculaire du melon : pourcentage de plantes mortes 3 mois après infestation des sols par des doses croissantes de F.o. f.sp. melonis.

Moyennes de 10 répétitions avec leur écart-type.

Receptivity of 4 soils to Fusarium wilt of muskmelon: percentage of wilted plants 3 months after soil infestation with F.o. f.sp. melonis at different concentrations.

Means of 10 replicates, with their standard deviation.
La figure 2 indique les pourcentages de mortalité obtenus dans ces 4 sols avec le couple lin-F.o. f.sp. lini. La grande sensibilité du sol d'Ouroux se manifeste à nouveau clairement ainsi que la résistance du sol de Châteaurenard. Mais le test lin apparaît plus discriminant et permet d'établir une courbe de mortalité pour le sol de Châteaurenard. Les sols de Sully et de Dijon présentent encore une réceptivité intermédiaire mais se rapprochent plus du sol sensible que du sol résistant. Il faut remarquer que les 2 courbes sont confondues aux faibles doses d'inoculum mais se différencient nettement pour la dose forte.

La forme de la courbe obtenue pour la terre Sully semble indiquer un palier à partir de la dose 1000 germes. Ce palier n'était pas visible sur la figure 1 , mais d'autres essais conduits avec le lin ont permis de le confirmer.

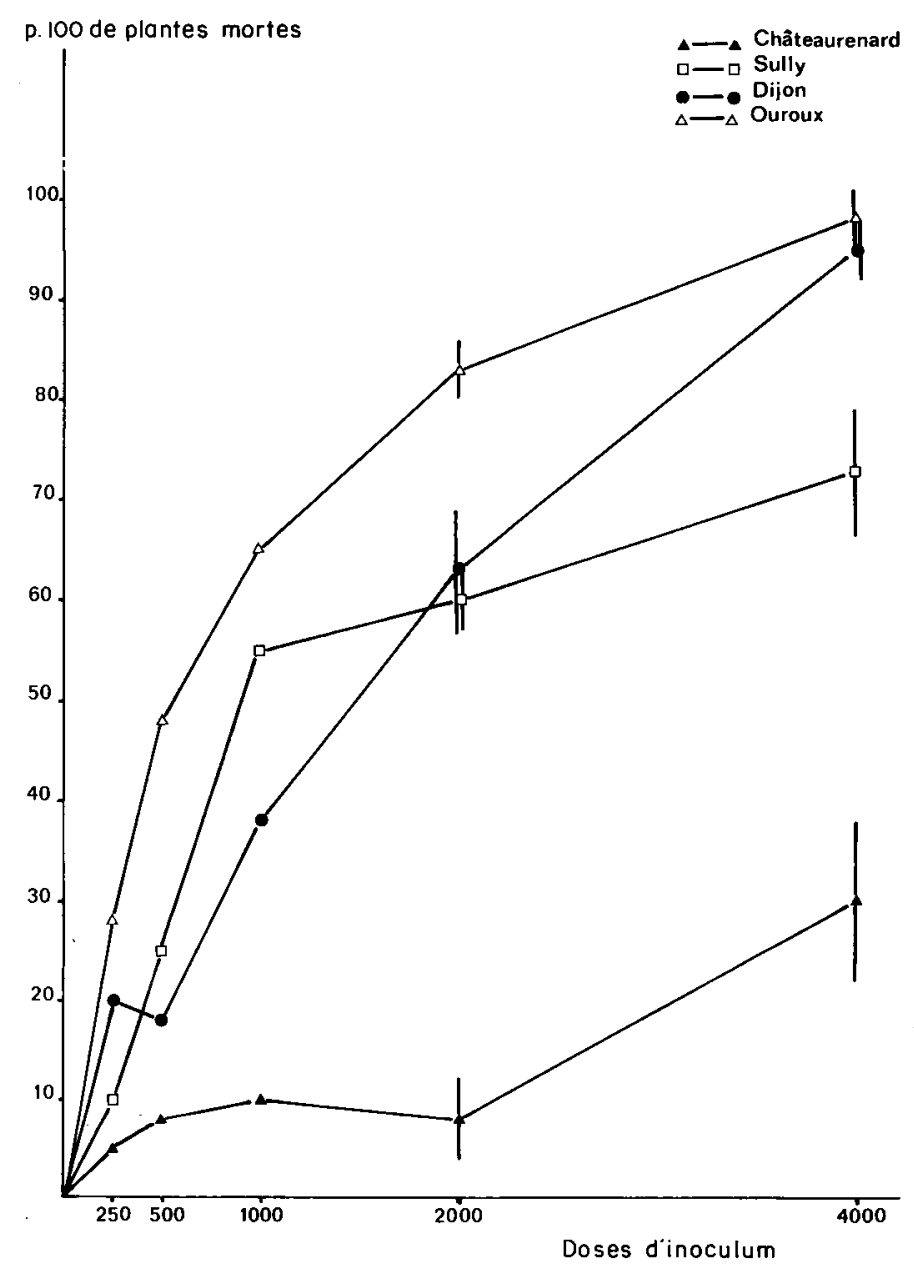

Figure 2

Réceptivité de 4 sols à la fusariose vasculaire du lin : pourcentage de plantes mortes 4 semaines après l'infestation des sols par des doses croissantes de F.o. f.sp. lini.

Moyennes de 12 répétitions avec leur écart-type.

Receptivity of 4 soils to Fusarium wilt of flax : percentage of wilted plants 4 weeks after soil infestation with F.o. f.sp. lini at different concentrations.

Means of 12 replicates, with their standard deviation.

\section{B. Comparaison du niveau de réceptivité de 2 substrats horticoles avant et après une culture de tomate}

A l'aide du modèle lin, la réceptivité de 2 substrats horticoles a été étudiée avant leur mise en culture, puis à l'issue d'une culture de tomates de 4 mois. La figure 3 


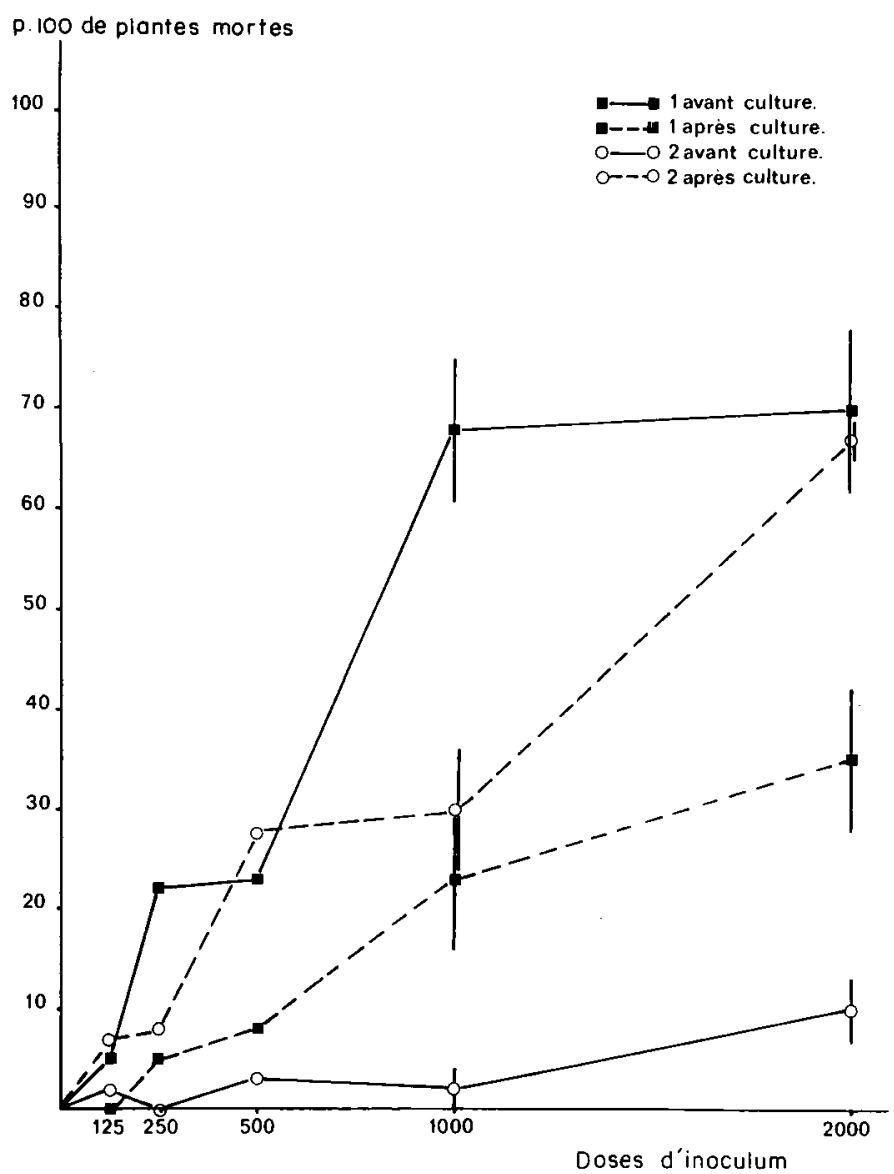

Figure 3

Comparaison de la réceptivité aux fusarioses de 2 substrats tourbeux, avant et après une culture de tomates: pourcentage de plantes mortes 5 semaines après infestation des substrats avec des doses croissantes de F.o. f.sp. lini.

Moyennes de 12 répétitions avec leur écart-type.

Comparison of Fusarium will receptivity of two peats before and after a tomato crop: percentage of wilted plants 5 weeks afier soil infestation with F.o. f.sp. lini at different concentrations. Means of 12 replicates, with their standard deviation.

indique qu'avant culture, le niveau de réceptivité du substrat 1 est beaucoup plus élevé que celui du substrat 2 . La situation est totalement inversée à l'issue de la culture; la réceptivité du substrat 1 a diminué alors que celle du substrat 2 a considérablement augmenté. Au cours de la culture les substrats évoluent, tant sur le plan physicochimique que sur le plan microbien, et cette évolution entraîne une modification de la réceptivité aux fusarioses vasculaires.

\section{Diminution de la réceptivité propre d'un substrat de culture par apport d'un tampon microbiologique}

Un mélange de 10 p. 100 (en volume) de terre résistante de Châteaurenard et de 90 p. 100 de tourbe blonde a été placé en incubation pendant 2 semaines, de façon à favoriser la colonisation du mélange par les microorganismes responsables de la résistance (LOUVET et al., 1976; RouXEL, 1978). La réceptivité de ce mélange a été comparée (à l'aide du couple lin-F.o. f.sp. lini) à celle de la tourbe seule et de la terre résistante. Les résultats présentés dans la figure 4 indiquent nettement que l'incorporation de 10 p. 100 de terre résistante à la tourbe blonde sensible permet de diminuer dans des proportions importantes la réceptivité de cette dernière. Les courbes de mortalité en

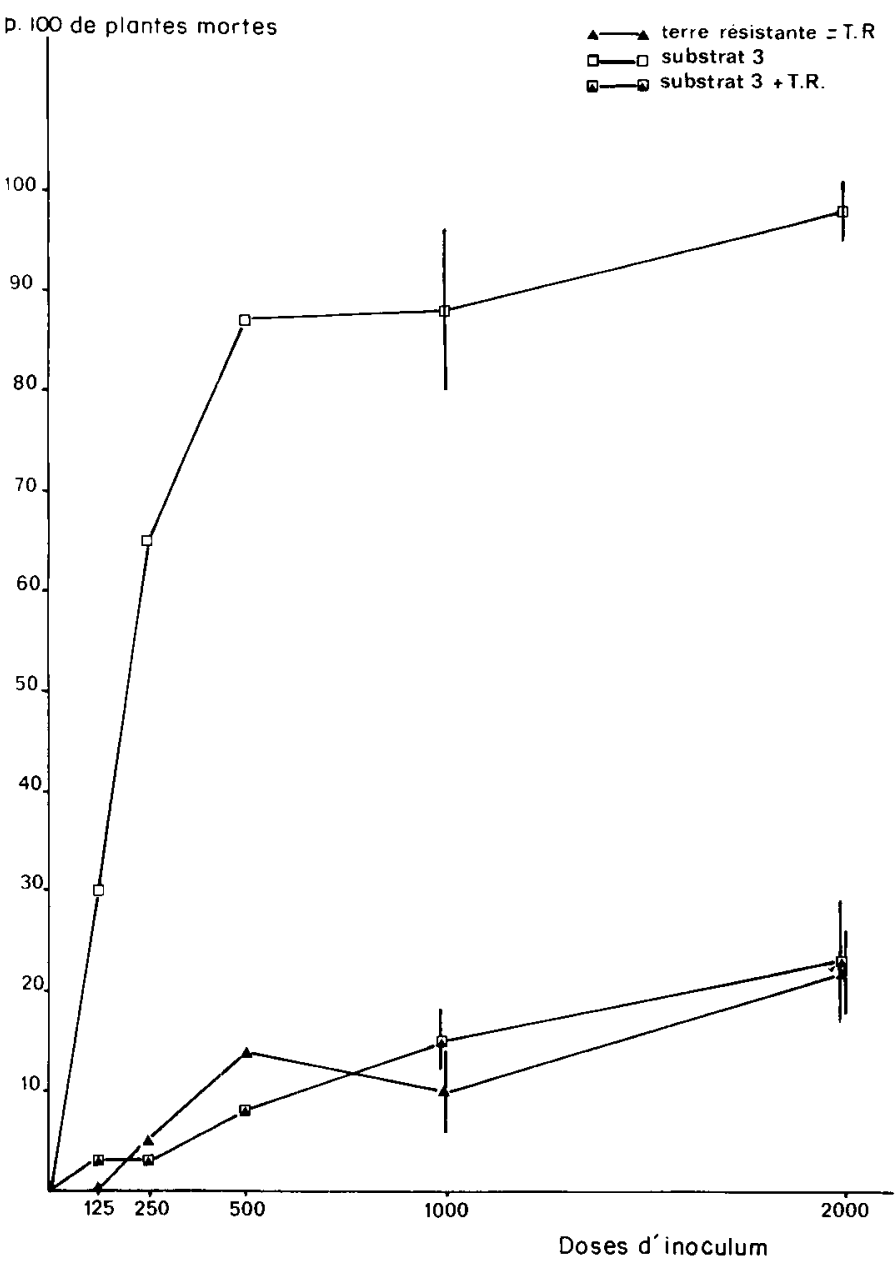

Figure 4

Diminution de la réceptivité d'un substrat tourbeux par apport de 10 p. 100 de terre résistante: pourcentage de plantes mortes 6 semaines après infestation des substrats avec des doses croissantes de F.o. f.sp. lini.

Moyennes de 8 répétitions avec leur écart-type.

Decrease of Fusarium wilt receptivity of a peat amended with 10 p. 100 suppressive soil: percentage of wilted plants 6 weeks after peat infestation with F.o. f.sp. lini at different concentrations. Means of 8 replicates, with their standard deviation.

terre résistante et en tourbe amendée sont confondues et indiquent donc un très bon niveau de résistance du substrat modifié.

Ces résultats acquis avec le couple lin-F.o. f.sp. lini ont été confirmés avec le couple tomate-F.o. f.sp. lycopersici (Sacc.) Snyder et Hansen, dans les conditions de culture en ferti-irrigation utilisées par les producteurs. Alors que toutes les plantes cultivées dans la tourbe infestée sont mortes, l'apport de 10 p. 100 de terre résistante a permis de protéger toutes les plantes pour la faible dose d'infestation (100 germes par ml) et 88 p. 100 des plantes pour la dose forte (1000 germes) de F.o. f.sp. lycopersici par $\mathrm{ml} \mathrm{de}$ substrat (AlabouvetTe et al., 1980c).

\section{DISCUSSION}

Les recherches consacrées à l'étude des sols résistants de Châteaurenard (LOUvET et al., 1976) ont permis de formuler le concept de réceptivité des sols aux fusarioses vasculaires. Si, dans les cas extrêmes de sensibilité ou de résistance, l'emploi d'une seule dose d'inoculum suffit à différencier la 
réceptivité des sols, des niveaux de réceptivité plus proches ne peuvent être mis en évidence qu'en utilisant une gamme croissante de doses d'inoculum. Le melon, plante avec laquelle nos travaux antérieurs ont été réalisés, est trop encombrant pour permettre la réalisation d'expérimentations importantes. Ayant démontré la spécificité de la résistance des sols de Châteaurenard vis-à-vis de l'ensemble des fusarioses vasculaires (ALABOUVETTE et al., 1980a), nous avons comparé les avantages respectifs de différents modèles hôte-parasite pour apprécier la réceptivité des sols. Notre choix s'est arrêté sur le couple lin-F.o. f.sp. lini qui fournit, dans un temps limité (6 semaines), les résultats les plus constants. La miniaturisation de ce test permet d'augmenter le nombre de répétitions et, par voie de conséquence, la précision des résultats acquis. Les expérimentations rapportées dans cet article ainsi que d'autres résultats (non publiés) acquis avec des sols résistants à la fusariose de l'œillet (TRAMIER et al., 1979) indiquent que le niveau de réceptivité d'un sol à la fusariose du lin est comparable à celui qu'il manifeste vis-à-vis des fusarioses du melon, de la tomate, de l'œillet ou du cyclamen. Il paraît donc possible de généraliser à l'ensemble des fusarioses vasculaires la réceptivité évaluée à l'aide d'un modèle donné. Grâce au gain de place et de temps, l'utilisation de la méthode lin-F.o. f.sp. lini incite à entreprendre la comparaison de la réceptivité de différents sols, avec les objectifs suivants : découvrir de nouveaux sols résistants, établir des corrélations entre réceptivité et propriétés agronomiques des sols (teneur et nature des argiles, des matières organiques, $\mathrm{pH}$...), étudier les modifications du niveau de réceptivité des substrats de culture sous l'effet de différents traitements (rotations culturales, fumures, traitements pesticides).

Si l'utilisation de cette méthode permet de comparer avec une précision satisfaisante le niveau de réceptivité des sols à un moment donné, elle ne permet pas, pour l'instant, de l'exprimer en valeur absolue. En effet, bien que les essais soient réalisés en chambre climatisée, de légères variations des conditions expérimentales sont toujours possibles d'un essai à l'autre et l'inoculum apporté dans le talc n'est pas parfaitement identique d'un lot de fabrication à l'autre. I1 est en effet constitué de plusieurs types de propagules dont l'énergie germinative est différente (TELLO-MARQUiNA et al., 1980). Enfin, la mesure du niveau de réceptivité des sols nécessiterait la linéarisation des courbes «mortalité-inoculum $»$. Or, il apparaît nettement (fig. 2) que la forme des courbes obtenues varie selon le sol ou le substrat de culture étudié. La forme des courbes est certainement un élément important qui traduit des interactions microbiologiques différentes. Il serait regrettable de perdre cette information et c'est pourquoi nous nous limitons, à l'heure actuelle, à la comparaison du niveau de réceptivité des sols en plaçant dans chaque essai un témoin de sensibilité (terre d'Ouroux) et un témoin de résistance (terre de Châteaurenard).

La réceptivité étant la résultante des facteurs de l'environnement biotique et abiotique du sol sur l'activité de l'inoculum pathogène, son niveau peut être modulé par des facteurs climatiques ou culturaux. La méthode proposée permet de le mettre en évidence, ce qu'illustre la figure 3. Une culture de tomates a profondément modifié le niveau de réceptivité des 2 substrats étudiés et cela dans un sens opposé. Mais cet exemple constitue un cas extrême, acquis avec des substrats de culture tourbeux très pauvres sur le plan microbiologique et évoluant considérablement au cours de la culture tant sur le plan agronomique que sur le plan biologique. Au contraire, l'expérience acquise avec des sols et en particulier les terres de Châteaurenard (RouXEL, 1978) et d'Ouroux indique que la résistance ou la sensibilité sont des caractéristiques fondamentales des sols et qu'elles n'évoluent que lentement sous l'influence des rotations culturales. Par contre, les variations rapides du niveau de réceptivité des substrats de culture peuvent s'expliquer par l'absence d'un tampon microbiologique puissant. C'est également pour cette raison qu'il est possible d'abaisser considérablement le niveau de réceptivité des substrats de culture par introduction d'une faible proportion de terre résistante (fig. 4). Il semble même que plus un substrat est réceptif aux fusarioses vasculaires, plus il est aisé d'y établir un bon niveau de résistance par introduction d'un tampon microbiologique.

Enfin, la détermination du niveau de réceptivité d'un sol de culture maraîchère est un élément intéressant permettant de prévoir le risque encouru par une culture. Si l'analyse de l'état sanitaire d'un sol avant culture renseigne sur le niveau d'infestation du sol, elle ne suffit pas à prévoir l'évolution de la maladie après infestation accidentelle. Au contraire l'estimation de la réceptivité permet de prévoir l'extension plus ou moins rapide de la maladie dans ce sol. La multiplication des analyses de réceptivité des sols permettra de préciser encore ces notions et de progresser dans la prévision des risques.

Recu le 11 mars 1981. Accepté le 15 septembre 1981.

\section{RÉFÉRENCES BIBLIOGRAPHIQUES}

Alabouvette C., Rouxel F., Louvet J., 1979. Characteristics of Fusarium wilt suppressive soils and prospects for their utilization in biological control. In Schippers R. and Gams W., Editors, SoilBorne Plant Pathogens, Academic Press, London, 165-182.

Alabouvette C., Rouxel F., Louvet J., 1980a. Recherches sur la résistance des sols aux maladies. VI. Mise en évidence de la spécificité de la résistance d'un sol vis-à-vis des fusarioses vasculaires. Ann. Phytopathol., 12 (1), 11-19.

Alabouvette C., Rouxel F., Louvet J., 1980b. Recherches sur la résistance des sols aux maladies. VII. Etude comparative de la germination des chlamydospores de Fusarium oxysporum et Fusarium solani au contact de sols résistant et sensible aux fusarioses vasculaires. Ann. Phytopathol., 12 (1), 21-30.

Alabouvette C., Tramier R., Grouet D., 1980c. Recherches sur la résistance des sols aux maladies. VIII. Perspectives d'utilisation de la résistance des sols pour lutter contre les fusarioses vasculaires. Ann. Phytopathol., 12 (2), 83-93.
Baker R., 1968. Mechanisms of biolugical control of soil-borne pathogens. Annu. Rev. Phytopathol., 6, 263-294.

Baker R., Maurer C. L., Maurer R. A., 1967. Ecology of plant pathogens in soil. VII. Mathematical models and inoculum density. Phytopathology, 57, 662-666.

Bouhot D., 1980. Le potentiel infectieux des sols. Thèse Docteur-èsSciences. Université de Nancy.

Hornby D., 1975. Inoculum of the take-all fungus : nature, measurement, distribution and survival. E.P.P.O. Bull., 5 (4), 319-333.

Louvet J., 1973. Les perspectives de lutte biologique contre les champignons parasites des organes souterrains des plantes. In Perspectives de lutte biologique contre les champignons parasites des plantes cultivées et des tissus ligneux, 48-58, Editeurs: Station fédérale de recherches agronomiques de Lausanne.

Louvet J., Rouxel F., Alabouvette C., 1976. Recherches sur la résistance des sols aux maladies. I. Mise en évidence de la nature 
microbiologique de la résistance d'un sol au développement de la fusariose vasculaire du melon. Ann. Phytopathol, 8 (4), 425-436.

Rouxel F., 1978. Etude de la résistance microbiologique des sols aux fusarioses vasculaires: application aux sols de la basse vallée de la Durance. Thèse Docteur-c̀s-Sciences, Université de Dijon.

Tello-Marquina J. C., Alabouvette C., Louvet J., 1980. Aptitude à la conservation des microconidies de Fusarium oxysporum f.sp. melonis. Ann. Phytopathol., 12 (3), 227-233.
Tramier R., Pionnat J. C., Bettachini A., Antonini C., 1979. Recherches sur la résistance des sols aux maladies. V. Evolution de la fusariose vasculaire de l'œillet en fonction des substrats de culture. Ann. Phytopathol., 11 (4), 476-481.

Zentmeyer G. A., Wallace P. P., Horsfall J. G., 1944. Distance as a dosage factor in the spread of Dutch Elm disease. Phytopathology, 34 (12), 1025-1033. In Guide to the use of terms in Plant Pathology, 1973, Phytopathological Papers, 17 p., 21, Editors C.M.I. 